\title{
Promoting Habits of Reflection and Self-Efficacy through Guided Reflection in an EFL Writing Course
}

\author{
Rudina Guleker \\ European University of Tirana \\ rguleker@qu.edu.qa
}

\begin{abstract}
Faced with high-stake assessments to document the mastery of the language, foreign language learners often feel a loss of confidence and perceived self efficacy, thus having negative effects on their academic performance as literature suggests. This study set out to look at the impact learner reflections at a university EFL writing course have on self-efficacy beliefs about the writing course and on the attitudes towards reflection in general. Results show that reflection increases self efficacy of the course and students see reflection as a valuable tool.
\end{abstract}

Keywords: self-efficacy, reflection, EFL writing.

\section{Introduction}

For decades educational psychologists have tried to propose solutions to low academic achievement by going back to the learner and putting him at the center of the process. Since, many learner centered theories and practices have taken the spotlight with the belief that the learner is an active player in the process and has an important role in his own academic journey. Thus, strategies, techniques and methods have been and are being developed to train him/her because many characteristics of a good learner can be taught. One area of interest in learner centeredness is learner beliefs which have preserved its momentum in the field of teaching and learning. For years, researchers have questioned wether self beliefs play a role in academic performance and success. Many studies in education have found that the beliefs students hold about themselves have an impact on their performance. Students who develop positive attitudes about their abilities or as known in literature students with high self-efficacy, are believed to perform better. Self efficacy beliefs are also associated with work related performance in many areas such as business, marketing, technology etc. (Gist \& Mitchell , 1992) as well as healthcare and sports.

Reflection on the other hand, ensures deep thinking while combining past, present and future experiences. Reflective thinking makes learning more meaningful and puts it in a broader context. Unfortunately, students at all levels and all subjects seem to struggle with it partly because of lack of direction or models. The purpose of this study is to look at the impact of structured written reflections in the perceived self-efficacy in writing tasks in an EFL writing classroom. The study description and result discussion will follow a general overview of self-efficacy and reflection concepts in education.

\section{Self-Efficacy}

Bandura (1993) describes perceived self-efficacy as "students' beliefs in their ability to regulate their own learning, master academic activities and determine their aspirations, level of motivation, and academic accomplishment" (p. 117). He (1997) reached to the conclusion that students with high self-efficacy persevere longer and search for deeper meaning across learning tasks. Pajares \& Schunk (2005) stated that these types of students have higher achievement at school. Bandura (1984) also noted that self-efficacy plays an important role in language learning by fostering or impeding it. Self efficacy differs from confidence in the sense that it is context specific. Therefore we can talk about self-efficacy within a specific activity, task or course framework. Self-efficacy is not a trait you were born with: it can change and be cultivated. Studies about self-efficacy have been carried out in many academic ares such as math, science, and writing and have been associated with positive effects on learning outcomes. 
(Klassen \& Usher, 2010; Pajares, 1996; Pajares \& Urdan, 2006). Schunk (1991) suggested that one of the sources of selfefficacy is learners' past performances. When learners have positive past experiences, their self efficacy seems to go up in subsequent tasks.

\section{Reflection}

Reflection is important today more than ever as we live in the age of instant gratification, opinion, and feedback among the myriad of information only a click away. Dewey is considered as one of the fathers of the definition of reflection and much of the literature written on this topic credits him for his contribution in this area. He suggested that reflective thinking is "an active, persistent, and careful consideration of any belief or supposed form of knowledge in the light of the grounds that support it, and the further conclusions to which it tends" (Dewey, 1910). There are other numerous definitions of reflective thinking, but all agree that it is not a loose, random, uncontrolled act. Rather, it is an active process, often initiated by a puzzle, problem or a need where the learners continuously assess what they know, need to know and consider the tools required for the process. Daydreaming or the "loose flux of disconnected material that floats through our minds" as Dewey puts it, is not "real thinking". Reflective thinking is disciplined, focused and geared towards a conclusion. As such, it can be said that training students to engage in reflective thought is not only an academic undertaking but it is required for action and advancement in the society. "The need of thinking to accomplish something beyond thinking is more potent than thinking for its own sake" Dewey (1910). Reflection helps us use the knowledge we have to make meaning of the new experiences. As Elliot (1943) put it a long time ago "learning and understanding learning processes does not happen maximally through experience alone but rather as a result of thinking about - reflecting on it". In language learning, for optimal learner autonomy Little (2007) suggests three crucial components: learner involvement, learner reflection, and target language use.

Despite the importance of reflection, many students, especially language learners fall short in this area. Teaching styles, culture, and perceived self-efficacy can have a serious impact on reflection. Riedinger (2006) states that to be effective reflective thinking in the classroom needs to be in alignment with the learning objectives and that students should be taught to reflect. Reflection, especially to students from different cultures and backgrounds, is an activity that does not come naturally. Riedinger (2006) warns: "students who are given vague instructions about the goal and objectives of portfolios and reflection, may become confused, frustrated, and resistant to further reflection". Literature suggests two approaches for reflection: unstructured and structured approach (Kidwai, et.al., 2010). The first one provides minimal guidelines and as such it can be challenging for language learners who still struggle with proficiency and getting their message across. The structured approach uses questions or prompts to help the learner focus their thinking in certain areas or aspects of the task. This study embraces the later approach as it was thought to be more suitable for the limited linguistic abilities of the language learners.

\section{Method}

This study employs a quantitative design to try to explore the effects of written reflections on the self-efficacy beliefs about the writing course and on beliefs about reflection as a viable strategy for future use. The added perspective of the practitioner researcher was thought to make data interpretation more thorough and meaningful. Two intact classes were used as a treatment and a control group. The independent variable manipulated in this study was a classroom reflection component and the dependent variable was self-efficacy beliefs.

\section{Participants}

36 students at a writing course in an intensive English preparatory program in a Middle Eastern University participated in the study. All the participants were females aged 17-22 with an equivalent of A2 English level. They were members of two intact classes, each assigned to a treatment group $(n=15)$ and a control one $(n=21)$. These students had to pass another higher level writing course before they moved to their respective majors. Consequently, the stakes were high and students' beliefs and confidence towards writing changed continuously. 


\section{Research Questions}

The research questions guiding this study were:

1. How did student participation in written reflection impact their self-efficacy ?

2. How did student participation in written reflection impact their attitudes towards reflection?

\section{Context of the Study}

The course used for the purposes of the study was a writing course designed in the form of a workshop where the writing process was at the center of all activities. As such, it aimed to foster an atmosphere of reflection and autonomy. Multiple drafts were written on different genre stated in the syllabus, with the help of peer and teacher feedback. Unfortunately, the culture of reflection did not embrace all the students. Many were focused on the end result, rather than learning bits and pieces from the process. In these circumstances, the author decided to explicitly cultivate reflection and look into how students' attitudes towards reflection and the perceived self-efficacy would be affected. The two intact classes used for the study belonged to two different semesters with the same syllabus and curriculum.

\section{Instruments and Procedure}

Two instruments (questionnaires) were used in the study. The first one consisted of self- efficacy items about the course (parts of it adapted from Pintrich and De Groot (1990)) and the second one was composed of reflection items about the reflecting process completed only by the treatment group. (adapted from Kirby 2009). The items were scored using a Likerttype scale ranging from 1 to 5 .

Participants in both groups were asked to complete the self-efficacy questionnaire in week 10 of the 15 week course. Starting week 2, the treatment group had to complete worksheets with reflection prompts at the end of the first and second drafts for each essay piece required in the syllabus which coincided

with week four, six, nine, and ten. The treatment group completed the "reflecting about reflection" questionnaire at the end of week 14 .

\section{Results and Discussion}

\section{$\mathrm{RQ} 1$}

Descriptive statistics for the self-efficacy questionnaire were run and the means were 35 for the treatment group and 31.57 for the control group. To determine wether this change is significant or not, a t-test for independent samples was conducted. The $p$ value was calculated as .0079 which shows a significance between the two groups. However, when calculating the effect size, the Cohen's $d$ was small which indicated a small effect size.

$\mathrm{RQ} 2$.

Of the 15 participants of the treatment group who wrote reflections on their essays, the majority chose either agree or disagree with the four items in the questionnaire. They agreed that their written reflections made their thoughts more focused and clear ( $Q 1)$, expanded their understanding of the topic and essay organization (Q 2), and motivated to review more carefully $(Q 3)$. The majority also agreed that they would like the same reflections to be part of their next writing course (Q 4). The table below

shows the overall results of the student responses for the questionnaire.

$\begin{array}{ccccc}\text { Ratings } & \text { Q1 Q2 } & & \text { Q4 } \\ & & & \\ & & & \\ & & 80\end{array}$




$\begin{array}{lllll}\text { SA } & 20 \% & 27 \% & 13 \% & 33 \% \\ \text { A } & 63 \% & 60 \% & 67 \% & 53 \% \\ \text { N } & 7 \% & 13 \% & 13 \% & 13 \% \\ \text { D } & 0 \% & 0 \% & 7 \% & 13 \% \\ \text { SD } & 0 \% & 0 \% & 0 \% & 0 \%\end{array}$

Learners are part of their learning process and their beliefs matter in their success. It is important that they develop positive beliefs in spite of hindering factors. The results of this study are in alignment with literature findings that many learner centered methods in writing instruction such as self-assessment and peer-assessment increase self-efficacy. Because of the consistent results about the effect of self-efficacy in attitudes, persistence, and performance, educators should strive to provide environments that foster it. One of the ways to do it is reflection not only about the task at hand but in connection with the goals that the learner sets and modifies continuously.

\section{References}

[1] Bandura, A. (1993). Perceived self-efficacy in cognitive development and functioning. Educational Psychologist, 28(2), 117-148.

[2] Dewey, J. (1910). How we think: A restatement of the relation of reflective thinking to the educative process. D.C. Heath and Co.

[3] Eliot, T. S. (1943). The four quartets. New York, NY: Harcourt, Brace, and Company.

[4] Evans, M. (2007). Another kind of writing: reflective practice and creative journals in the performing arts. Journal of Writing in Creative Practice, 1(1), 69-76.

[5] Gist, M.E., Mitchel, T.R. (1992). Self-efficacy: A theoretical analysis of its determinants and malleability. Academy of Management Review, 17(2): 183-211.

[6] Little, D. (2007). Language learner autonomy: Some fundamental considerations revisited. Innovation in Language Learning and Teaching, 1(1), 14-16.

[7] Joët, G., Usher, E. L., \& Bressoux, P. (2011, June 20). Sources of Self-Efficacy: An

[8] Investigation of Elementary School Students in France. Journal of Educational Psychology.

[9] Advance online publication. doi: 10.1037/a0024048

[10] Kidwai, K., Johnson, G., Hsieh, P.H., Hu, R. (2010). Promoting reflective thinking through e-portfolios. The EPortfolio Paradigm: Informing, Education, Assessing, and Managing with E-Portfolios. Informing Science Press.

[11] Kirby, L.(2009). Another look at reflection: Promoting student voice, self-efficacy and student/teacher dialogue through structure, guided reflection prompts in a college reading and study skills course. Doctoral Dissertation.

[12] Pintrich, P. R., \& De Groot, E. V. (1990). Motivational and self-regulated learning components of classroom academic performance. Journal of Educational Psychology, 82(1), 33-40.

[13] Riedinger, B. (2006). Mining for meaning: Teaching students how to reflect. In A. Jafari \& C. Kaufman (Eds.), Handbook of Research on E-Portfolios (pp.90-101). Hershey PA : Idea Group Reference.

[14] Schunk, D. (1991). Self-efficacy and academic motivation. Educational Psychologist, 26, 207-231.

Appendix A

Reflection about Reflecting Questionnaire

1.Writing a reflection made my thoughts clearer or more focused than they were before.

2.My understanding of the topics and the essay organization grew as a result of writing the reflections.

3.Writing a reflection motivated me to review my essay more carefully.

4. I recommend that the reflection assignments continue next semester in the writing course. 